\title{
Adaptation of the submerged pumps intended for the irrigation in the arid regions
}

\section{CHEBIHI Lakhdar, KHODJET KESBA Omar}

Laboratory of Mobilization and valorization of the water resources Ecole Nationale Supérieure de 1'Hydraulique, RN n 29, BP 31, Soumaâ, Blida 09000, Algeria

\section{Email address:}

thegreen_only@yahoo.fr (C. Lakhdar),okhodjet@yahoo.fr (K. K. Omar)

\section{To cite this article:}

CHEBIHI Lakhdar, KHODJET KESBA Omar. Adaptation of the Submerged Pumps Intended for the Irrigation in the Arid Regions. Journal of Water Resources and Ocean Science. Vol. 3, No. 2, 2014, pp. 17-21. doi: 10.11648/j.wros.20140302.11

\begin{abstract}
The first area of work is to study only submersible pumps PUVAL "Pumps Valves" of Berrouaghia. While tracing the effects of abrasion on submersible pumps installed in the shelters in drilling and suffered the consequences are for irrigation in arid areas. The second line stain work to answer the following position: "Should we fight against the causes and not against the consequences?" The result of the proposals will help manufacturers to pump Algerian, one with the best hydraulic performance for the chosen material. Certainly, there have been abrasion tests on samples, but determining the duration of wear and the wear rate of the types of materials is always a line of news. Increasing the life of the pump while remaining within the proper range of operation.
\end{abstract}

Keywords: Optimization, Energy, Wheels, Abrasion, Performances

\section{Introduction}

In Algeria, and more particularly in the Sahara, the independent source of satisfaction of the demand for water it is the subterranean water, because of the aridity of the climate and the relatively easy exploitation of this underground resource.

The population growth, drillings albian, and the modernization of agriculture involve a major problem either by the reduction in the quantity or by the deterioration of the quality of this underground source by causing an unfavorable process of this subterranean water evolutionary in the space and the time, which present a current problem and remain not easily controllable.

Our zone of study, namely the wilaya of Ghardaïa, is located in an area Saharan, the repetitive dryness's and the limitation of the water resources did not allow the valorization of the enormous efforts authorized as regards agricultural hydro installations from where the development of the exploitation of the tablecloth.

\section{General Information on the Wilaya of Ghardaïa}

Ghardaiia is located at the center of the Northern part of the Sahara Algerian, It counts 13 communes distributed out of 03 daïras and covers a surface of $86,560 \mathrm{~km}^{2}$. [15]

The valley of M'Zab, founded in XI century, is a true museum with open sky located in full desert and covering a surface of $50 \mathrm{~km}^{2}(20 \times 2,5 \mathrm{~km})$. It is classified like national heritage in 1971 and inheritance of humanity by UNESCO since 1982.

Table 1. Surfaces of the communes of the wilaya [15].

\begin{tabular}{cc}
\hline Communes & Superficies $\left(\mathbf{K m}^{\mathbf{2}}\right)$ \\
\hline Ghardaïa & 300 \\
El-Menia & 27000 \\
Daya & 2175 \\
Berriane & 2250 \\
Metlili & 7300 \\
Guerrara & 2900 \\
EL-Atteuf & 750 \\
Zalfana & 2220 \\
Sebseb & 5640 \\
Bounoura & 810 \\
Hassi El-F'hel & 6715 \\
Hassi El-Gara & 22000 \\
Mansoura & 6500 \\
Total & 86560 \\
\hline
\end{tabular}




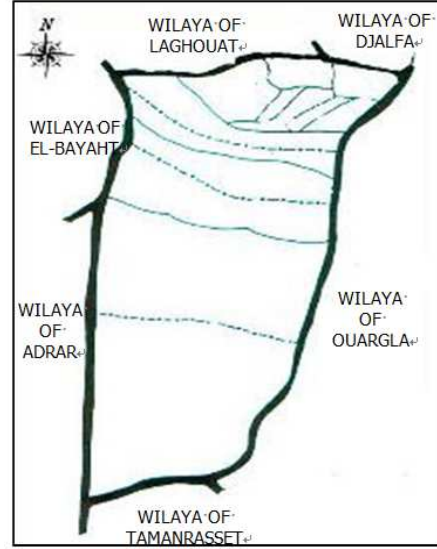

Figure 1. Localization of the wilaya.

\subsection{Systems of Collecting of Subterranean Water}

The subterranean water is preferred because it allows the space extension of the farms and because the works of collecting occupy of reduced spaces. It is presented by drillings of well going beyond the $50 \mathrm{~m}$ of depth and the realization to this level of galleries of collecting of source and storage. [13]

According to the monograph of the wilaya, the hydraulic systems are the following:

$\checkmark \quad$ Systems of collecting of subterranean water by the drilling of well exceeding $50 \mathrm{~m}$ depths, and the realization of galleries of collecting of source and storage: kind of system of Foggara. [15]

$\checkmark \quad$ The systems storages of the water of believed by the realization of the dams of reserves in the level of palmerais and small tanks in each garden.

\subsection{Resource of Subterranean Water}

\subsubsection{The Final Complex}

The tablecloth of the Final Complex is contained in the various permeable horizons of the higher Cretaceous and the Tertiary sector. It extends in Algeria on a vast territory going from the dorsal from M'zab in the West until the hamada from Tinhert in the South. [12]

\subsubsection{The Continental Guide}

In geology, the Continental Guide indicates the continental formations which settled between the marine cycle of Paleozoic closes by orogenesis hercynienne and the marine invasion of Cénomanien. It covers a broad period of Sorted with the albian.

\subsection{Drillings}

The first drillings albian carried out in 1948 and 1950 . The gushing impressing of subterranean water revealed the importance of the tablecloth contained in the sandstones of the Continental guide. [04] [14]

From this period, the number of drilling did not cease increasing. The wilaya account currently more than 288 drillings, which arise as follows:

75 for drinking water supply DWS ; 108 for the irrigation IRR ; 5 for the water supply for industry WSI ; 24 in mixed matter DWS and IRR ; 76 drillings not exploited for various reasons (equipment, not electrified...) [15]

\section{Abrasive Wear}

Abrasive wear is defined as being wear by displacement of matter transported by hard particles or hard protuberances. Thus abrasive wear is the result of the sliding friction by tilling or plastic deformation. Wear can be done with two bodies, directly starting from the solids in contact or with three bodies. [5] [10]

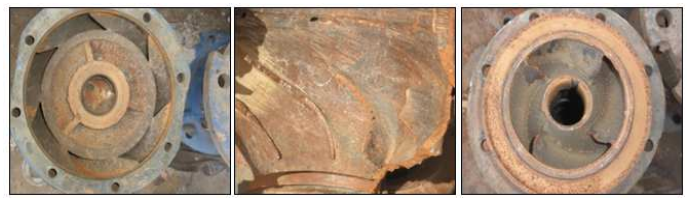

Figure 2. Pump housing immersed damaged by abrasion.

\subsection{Diagrams of the Mechanisms of Abrasive Wear}

According to the severity of the contact, several transformations of abraded surface occur. They depend on the mechanical properties and the geometry of materials in contact. If the surface of the solid solicited is regarded as perfectly planes, the following damages can be observed: cross, if the abrasive is sufficiently sharpened;

$\checkmark$ embossing of the matter on the surface;

$\checkmark \quad$ fracturing, if the solid is fragile;

$\checkmark$ Removal of grains, if the material is insufficiently homogeneous.
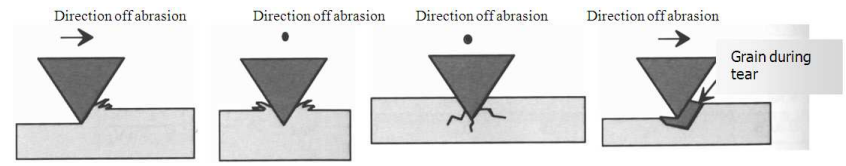

Figure 3. Diagrams of the mechanisms of abrasive wear [10].

\subsection{Symptoms of Wear}

The symptoms of wear are caused so much by the presence of these bubbles, like by their later collapse or of the implosion. [1]

The symptoms include/understand: A sudden fall of the discharge pressure, Popcorn noise of bursting, vibrations, sometimes violent, a deaf noise, Loss of great listening, a wear fish scales on the back face of the frequent need and turbine blades to adjust packing tree. [7]

\subsection{Factors Influencing Wear}

The depression during which a given pump starts to use depends on several factors: quantity of sand; the quality of sand; the total head total of the pump; the type of wheel; vibration (frequency and amplitude); penetration depth; carrying fluid (natural, circulation terms); tool (natural of material, forms and dimensions); part (natural of material, forms to realize). [11] 


\subsection{Parameters Influence Abrasive Wear}

The quantity of the metal of the abrasive furrow eliminated from surface in the form of particles of wear compared to that affected by the plastic deformation is relatively weak, approximately $10 \%$ to $20 \%$ on average. This removed quantity depends on many parameters and more particularly by hardness and the form on the particles abrasives.

\subsubsection{Hardness}

When the hardness of striped surface approaches that of the abrasive, this one blunts, decreasing its aptitude for the cut. [6] [8]

\subsubsection{The form}

The form of the active part of the abrasive, if it presents sharp angles, suitably directed compared to the direction of slip, abrasion will be similar to a process of cut and the left trace will be indicated like a stripe of micro cut. [3]

\section{Methods and Diagnoses}

In order to achieve our goals, the followed step consists of prospections of several forms:

- Documentary prospections: it is carried out near the various services of DHW, AOW, NOC, NAHR and NOID. These prospections aim to characterize the zone of studies and to determine the problems well.

- Prospections on the ground near the farmers, of the suppliers of material of pumping and the companies of drilling. The prospections were carried out in the racks Hassi El-F'hel (F1, F2, F3 and F4) most developed as regards exploitation of subterranean water.

Work within the framework of the project has enabled to us to approach the socio-economic and technical context submerged pumps used for the management of subterranean water thanks to the training courses organized in the perimeters.

\subsection{The Sample}

With an aim of having a sample of the submerged pumps used by the farmers who exploit the tablecloth, it is necessary to leave on the site and carries out an inventory which locates at least the intake points (drillings of the private farmers).

Measurements of the flows for subterranean water were taken without any indication of the surfaces in addition to the coordinates which do not correspond inevitably to the data of the farmers.

\subsubsection{Evolution of the Outputs}

The farmers distinguish three successive periods:

$\checkmark$ Period before the dryness's characterized by the availability of water and the acceptable outputs $\checkmark \quad$ Period during the dryness's characterized by the fall of the outputs;

$\checkmark \quad$ Period of implementation of the pumping which made it possible to make up the deficit out of water and a certain improvement of the farming techniques

\subsubsection{Oncern}

To supplement the information received from the farmers, it was necessary to consult the company's suppliers of the equipment and the services. Main concerns which interest us are:

$\checkmark$ To characterize the sector of private pumping and the methods of intervention in decision making and for the installation;

$\checkmark$ To define the characteristics of the material of pumping.

\subsection{Tests of Pumping}

The tests of pumping constitute a preliminary stage before the exploitation of a given work, they are necessary to avoid the interferences between nearby works and to plan the flows and the schedules of operation of pumping for a whole long-term area in order to prevent the causes of wears for the pump. [2]

They consist in pumping during a certain time until the stability of the water level to the permanent mode in the objective to optimize the exploitation of the work (flow, time of pumping and the optimal position of the pump) and to consider the characteristics hydrological of the tablecloth to be exploited.

\subsection{Methods of Analysis of the Data}

The results of the prospections were individually treated then in a total way to detect the relations which exist to reach the ideal output with the use of these submerged pumps from point of view lasted life (operation), better output at end as much as possible to avoid the risks of wears generated by the particles of sands.

We tried in this study to integrate economic factors and organizational affecting the decisions of the farmers for better determining the problems.

The economic study was carried out while being based on the technical routes of each culture such as they are practiced by the farmers and by consulting some companies sometimes. The breeding's are not treated in this study considering unreliability of the results of the prospections.

\subsection{Diagnosis of the Operation of the Pump}

The THG (Total Height Gauge) is calculated under the most underprivileged conditions and by taking account of the pressure losses caused by the various bodies of the installation.

One calculation outputs mechanical $\eta_{\mathrm{m}}=\mathrm{P}_{\mathrm{m}} / \mathrm{P}$ and the total output $\eta_{\text {global }}=P_{n} / P$ 
Table 2. Calculation of the total outputs of the pumping plants.

\begin{tabular}{cccccc}
\hline drillings & HMT (m) & $\mathbf{Q}\left(\mathbf{m}^{\mathbf{3}} \mathbf{/ s}\right)$ & $\mathbf{P}(\mathbf{K w})$ & $\mathbf{P}_{\text {moyen }}(\mathbf{K w})$ & $\begin{array}{c}\square \text { global } \\
\mathbf{( \% )}\end{array}$ \\
\hline F.1 & 37,95 & 0,02 & 5,73 & 31,32 & 18 \\
F.2 & 33,15 & 0,01 & 2,68 & 31,32 & 9 \\
F.3 & 40,14 & 0,01 & 4,73 & 10 & 47 \\
F.4 & 36,43 & 0,02 & 6,85 & 41,76 & 16 \\
\hline
\end{tabular}

The following remarks arise from table 2:

- The total output generally lower than the average output of each pump is immersed;

- The report $\mathrm{R}_{\text {global }} / \mathrm{R}_{\text {normal }}$ measures the effectiveness of the material, more it moves away from the unit plus the output of the material concerned is abnormal. This calculation deduced distinguished two groups, the first includes the F.2 pump having reports/ratios lower than $20 \%$, and the second relates to the remainder of the pumps which have reports/ratios beyond $47 \%$. the first group is in a situation of abnormal operation compared to the second;

- The installations fed starting from the electrical communication have the best outputs; the remainder of the exploitations can be classified according to the technique of adopted irrigation.

- The output of the oldest installations is weakest.

The bad dimensioning of the material of pumping noted in certain visited installations is the origin of poor yield. The bad condition of the material, rare talks and repairs (do-it-yourself) which are carried out only when the breakdowns are serious contribute in a way important to reduce the outputs and to increase the cost of pumping.

\section{Profitability of the Submerged Pump}

\subsection{Loads}

Pumped volumes are estimated on the basis of technical route of each culture such as they are practiced by the farmers. These routes made it possible to evaluate the frequency of the irrigations and the operating hours of motor-driven pump group for each culture at the majority of the farmers. If the farmer is not able to remember the details, it puts estimates using planning's of the irrigations; if not, a total volume can be estimated starting from the loads of energies, the exploitation in this case is not taken into account in detailed calculations.

Table 3. The calculation of cost of pumping (fixed costs).

\begin{tabular}{|c|c|c|c|c|c|c|c|c|}
\hline \multirow[b]{2}{*}{ Drillings } & \multirow[b]{2}{*}{$\begin{array}{l}\text { Digging of wells } \\
\text { (DZD) }\end{array}$} & \multicolumn{3}{|c|}{ Basic investment } & \multicolumn{3}{|c|}{ Fixed costs } & \multirow[b]{2}{*}{$\mathrm{C} 1+\mathrm{C} 2$ (DZD) } \\
\hline & & $\begin{array}{l}\text { Pumps } \\
\text { purchase (DZD) }\end{array}$ & $\begin{array}{l}\text { Shelter } \\
\text { (DZD) }\end{array}$ & C1 (DZD) & Repair (DZD) & Maintenance (DZD) & C2 (DZD) & \\
\hline D.1 & 144000 & 152000 & 20000 & 15600 & 31000 & 8240 & 39240 & 54840 \\
\hline D. 2 & 41000 & 212000 & 40000 & 16832 & 34800 & 15600 & 50400 & 67232 \\
\hline D. 3 & 220000 & 200000 & 0 & 20668 & 0 & 10000 & 10000 & 30668 \\
\hline D. 4 & 289800 & 280000 & 16000 & 28860 & 24000 & 14880 & 38880 & 67740 \\
\hline
\end{tabular}

\section{Loads of Production}

seeds; with the purchase of fertilizers; with mechanized work; and with labor. The table recapitulates the results

They include the loads relating to the purchase of the

Table 4. loads of production.

\begin{tabular}{|c|c|c|c|c|c|}
\hline cultures & Drillings & $\begin{array}{l}\text { Total loads } \\
\text { DZD }\end{array}$ & $\begin{array}{l}\% \text { additional expenditure related to the } \\
\text { irrigation by Loads report/ratio of irrigation }\end{array}$ & $\begin{array}{l}\text { \% Loads of irrigation } \\
\text { compared to the total loads }\end{array}$ & $\begin{array}{l}\% \text { Fresh of pumping } \\
\text { compared to the total ones }\end{array}$ \\
\hline \multirow{4}{*}{$\begin{array}{l}\text { Durum } \\
\text { wheat }\end{array}$} & D.1 & 6914 & 15 & 48 & 83 \\
\hline & D. 2 & 2721 & 30 & 3 & 56 \\
\hline & D. 3 & 31538 & 23 & 58 & 71 \\
\hline & D.4 & 41196 & 21 & 31 & 73 \\
\hline \multirow{3}{*}{ Barley } & D.1 & 1074 & 13 & 7 & 85 \\
\hline & D. 2 & 23152 & 5 & 25 & 96 \\
\hline & D. 4 & 28287 & 20 & 21 & 75 \\
\hline Tomato's & D. 4 & 11896 & 8 & 9 & 92 \\
\hline \multirow{3}{*}{$\begin{array}{l}\text { But; } \\
\text { fodder }\end{array}$} & D. 1 & 6541 & 13 & 45 & 85 \\
\hline & D. 2 & 68272 & 2 & 72 & 95 \\
\hline & D. 4 & 52070 & 5 & 39 & 94 \\
\hline
\end{tabular}

According to this calculation, the following elements arise:

\section{- Durum wheat}

The loads of irrigation vary from $15 \%$ of which $83 \%$ are consisted the expenses of pumping, with $30 \%$ whose pumping occupies $56 \%$.

- Barley
The loads of irrigation are weaker even if they have priority. The loads of irrigation occupy from 07 to $25 \%$ whose expenses of pumping represent from $75 \%$ to $96 \%$.

- Cultures of summer

The other loads of the market gardening dominated the loads of irrigation thus the contribution of the irrigation varied between $09 \%$ and $72 \%$. For corn, the irrigation 
could reach $72 \%$ of the total loads including $95 \%$ only consisted the expenses of pumping. The additional expenditure related to the irrigation is weaker and do not exceed $13 \%$ of the loads of irrigation.

\section{Conclusion}

The discussions with the farmers showed that fodder and the corns are the principal cultures practiced for a long time with the introduction from time to time of the market gardening on more or less limited surfaces. Generally, one can speak about a single strategy consisting with the culture of the same speculations in spite of the recourse to pumping, in other term, generally pumping is only one means to restore their cultivation methods before the dryness, are added to the two criteria of priority (corns and fodder), the control of the practices of a culture (truck farming) which encourages the farmers to specialize.

The intervention of the costs of pumped water are more dominant compared to the other loads of irrigation, therefore the control of device of pumping such as the installation, the chock, maintenance and repair are the essentiaux factors such as wear by abrasion of the wheels by the crucial factor which is fine sand which intervenes directly if one speaks about the profitability of the submerged pump. New processes invented to reduce the quantity of sand entering a submerged pump in a drilling, is done either by a system of convergent cone perforated along the strainer casing and submerged pump, or by a very new system 'cyclone' to avoid any quantity of sand returning inside the immersed suction filter. In order to make profitable the pump from the consumption point of view of electrical energy, better output, therefore improvement of the lifespan of the pump.

\section{Nomenclatures}

D.W.S: Drinking Water Supply

W.S.I: Water Supply for Industry

AOW: Algerian Of Water

NAHR: National Agency of the Hydraulic Resources

$\mathrm{C}_{1}$ : the sum of the loads of basic investment.

$\mathrm{C}_{2}$ : the sum of the fixed charges.

DHW: Direction of Hydraulics of Wilaya

DZD: Algerian Dinars

F: Force applied [N]

THG: total height gauge $[\mathrm{m}]$

IRR: Irrigation

NOC: National Office of the Cleansing

NOID: National Office of the Irrigation and the Drainage
$\mathrm{P}_{\mathrm{m}}:$ Weight $[\%]$

$\mathrm{P}_{\mathrm{v}}$ : Volume $[\%]$

PUVAL: PUmp Valve Algerian

$\mathrm{Q}:$ Flow $\left[\mathrm{m}^{3 . \mathrm{s}-1}\right]$

\section{References}

[1] WHITE, K.B; TAYLOR, S.E; "Pumping low yielding wells with conventional submersible pumps", Ground water monitoring and remediation (USA), (1995).

[2] GENETIER B; "La pratique des pompages d'essai en hydrogéologie", Manuels et méthodes du B.R.G.M, $\mathrm{N}^{\circ}$ 9, France, (1984).

[3] CEMAGREF; "Les stations de pompage individuelles pour l'irrigation", (1996).

[4] MABILLOT, A ; "Le forage d'eau", Guide pratique, (1988).

[5] JEANMARIE GEORGE ; "Frottement, usure et lubrification", Eyrolles, (2000).

[6] GODET, M ; "Les fondements mécaniques de la tribologie", Mécanique Matériaux Électricité, (1972).

[7] DERRIEN, JACQUES ; "Surface des solides, propriétés électroniques", Paris, Techniques de l'Ingénieur, (1990).

[8] JEAN DHERS; "Usure, avaries et corrosion", Facteur de destruction des matériels industriels, (1978).

[9] J. AYEL ; "Les lubrifiants, moteur et pertes par frottement et usure", Institut Français du Pétrole, (1979).

[10] JEAN BLOUET; "Usure et frottement", T. ing. A 3139.

[11] R. BUTIN, M. PINOT; "Fabrications mécaniques", Technologie, tome 1, (1981).

[12] UNESCO; "Etude des Ressources en Eau du Sahara Septentrional", Rapport sur les résultats du Projet REG-100, UNESCO, Paris, (1972).

[13] OSS ; "Système Aquifère du Sahara Septentrional", Rapport interne. Annexes. Tunis, Tunisie, 229p, (2003a et b).

[14] BRL ingénierie ; "Etude du Plan Directeur Général de Développement des Régions Sahariennes", Lot I. France, 94p, (1999).

[15] Projet DELTA ; "Développement Des Systèmes Culturels Territoriaux, Plan d'action, cas de Ghardaïa", (2003).

[16] http://www.google.com/earth/

[17] http://en.wikipedia.org

[18] http://www.hardide.com/applications/coatings-for-pumps/

[19] http://www.poval.com.dz/. 